\title{
A percepção do profissional contábil no processo de convergência nas pequenas e médias empresas na região metropolitana do Recife - PE
}

\section{A professional optics in accounting convergence process in small and medium companies in the metropolitan region of Recife - PE}

\author{
Adilson Antônio dos Santos \\ Faculdade Santa Helena \\ Maria das Graças Silva \\ Faculdade Santa Helena
}

Solange Gomes de Aguiar

\author{
João Gabriel Nascimento de Araújo \\ Universidade Federal de Pernambuco \\ Brasil \\ Juliana Gonçalves de Araújo \\ Universidade Federal de Pernambuco \\ Brasil
}

Data de submissão: 07/01/2017

Data de aceite: 16/02/2018

\section{RESUMO}

O objetivo deste artigo é verificar a ótica do profissional contábil no processo de convergência das normas contábeis nas pequenas e médias empresas na região metropolitana do Recife/PE. A coleta de dados foi realizada através da aplicação de questionários a uma amostra de 40 profissionais contábeis em pequenas e medias empresas da região metropolitana do Recife - PE. Os resultados sinalizam que os respondentes não desconhecem totalmente $\mathrm{o}$ atual processo de convergência da contabilidade brasileira aos padrões 
internacionais, no entanto, a aplicabilidade dos procedimentos contábeis em conformidade com o Pronunciamento Técnico destinado às pequenas e médias empresas tem ocorrido parcialmente quando as práticas coincidem com aquelas que usualmente já estavam sendo executadas de forma pragmática.

Palavras-chave: Profissional contábil; Pequenas e médias empresas; Convergência contábil; padrões internacionais; Pronunciamento técnico PME.

\section{ABSTRACT}

The objective of this article is to verify the perspective of the accounting professional in the process of convergence of accounting standards in small and medium enterprises in the metropolitan region of Recife / PE. Data collection was carried out through the application of questionnaires to a sample of 40 accounting professionals from small and medium enterprises of Recife - PE metropolitan area. The results indicate that the respondents are not totally unaware of the current process of convergence of Brazilian accounting to international standards, however, the applicability of accounting procedures in accordance with the Technical Pronouncement for small and medium enterprises has occurred partially when the practices coincide with those Which were usually already being executed pragmatically.

Keywords: accounting professionals; Small and medium enterprises; Accounting convergence; international standards; Standard technical SMEs.

\section{INTRODUÇÃO}

Os atores contábeis no Brasil, buscando reduzir as divergências contábeis vem se adaptando para uma nova realidade, tendo em vista a necessidade de gerar informações contábeis úteis a outros usuários alem de governo e credores, e que sejam compreendidas internacionalmente.

Diante desse novo cenário em que se observa a expansão dos negócios, além das fronteiras do país, visando a presença de investidores como fonte alternativa de capacitação de recursos para entidade, surge à necessidade de uma linguagem contábil global, tendo como objetivo alcançar a transparência e acessibilidade das demonstrações contábeis a todas as partes interessadas nos negócios da empresa além da redução de custos e melhorias nos lucros almejados pelas entidades.

Neste sentido, a resolução CFC n ${ }^{\circ}$ 1055/05 afirma que a importância crescente da Contabilidade levou a tendência mundial de se contar, no processo de emissão de pronunciamentos contábeis, com a participação não só dos contadores preparadores das informações dessa natureza e dos seus auditores independentes, mas também a dos usuários dessas informações, como os profissionais de investimentos e órgãos reguladores dos que fiscalizam esse processo e dos que pesquisam e estudam a Ciência Contábil. A confiabilidade 
das demonstrações contábeis por toda a sociedade interessada torna-se maior quando uma entidade for responsável pelo preparo e pela emissão e divulgação das regras que as regem. O Conselho Federal de Contabilidade (CFC), através da Resolução CFC 1.255/2009, aprovou a NBC T 19.41 que trata especificamente sobre às regras aplicáveis na Contabilidade de pequenas e médias empresas, considerando o que foi exposto no Pronunciamento Técnico PME, emitido pelo Comitê de Pronunciamentos Contábeis (CPC).

O CPC emitiu em separado este Pronunciamento Técnico PME para aplicação às demonstrações contábeis para fins gerais de empresas de pequeno e médio porte, conjunto esse composto por sociedades fechadas e sociedades que não sejam requeridas a fazer prestação pública de suas contas. Com o objetivo de viabilizar a adequação das pequenas e médias empresas ao IFRS, o Comitê de Pronunciamentos Contábeis através do Pronunciamento Técnico PME define a forma destas empresas adequarem sua Contabilidade a nova legislação. A viabilidade da adequação ocorre através da simplificação das demonstrações contábeis, considerando a estrutura das pequenas e médias empresas.

Assim, após um ano de exigência da aplicação do pronunciamento que regula a convergência da Contabilidade brasileira aos padrões internacionais das pequenas e médias empresas, e sabendo que a maioria dos contabilistas do Brasil prestam serviços a essas empresas, observa-se a relevância e a inquietação em responder ao seguinte questionamento:

Qual a percepção do profissional contábil no processo de convergência das normas contábeis nas pequenas e medias empresas na região metropolitana do Recife/PE?

A fim de responder ao questionamento, o objetivo é identificar a percepção dos contabilistas que atuam em toda região metropolitana do Recife - PE sobre o processo de convergência contábil das pequenas e médias empresas aos padrões internacionais de Contabilidade.

Além da introdução, o presente artigo se subdivide em mais quatro seções. Na segunda seção é apresentada a fundamentação teórica que abordará harmonização, padronização e convergência das práticas contábeis, Pronunciamento Técnico PME e as diferenças entre o pronunciamento técnico PME e o CPC completo. Na sequência, a terceira seção destina-se à exposição dos procedimentos metodológicos empregados no estudo. A quarta seção exibe a análise dos dados coletados e, por fim, na quinta seção tem-se a conclusão da pesquisa.

\section{FUNDAMENTAÇÃO TEÓRICA}




\subsection{Harmonização, padronização e convergir as práticas contábeis aos padrões internacionais}

Amenábar (2001) já destacava que a harmonização contábil é o processo onde vários países de comum acordo realizam mudanças nos seus sistemas e normas contábeis, para torná-las compatíveis, partindo de uma teoria geral de contabilidade e um marco conceitual comum que fundamenta suas normas, respeitando as características de cada país. Para um melhor entendimento do processo de harmonização das práticas contábeis, Perez Junior (2009) diz que Padronização: São adoções de regras mais rígidas, sem flexibilização. Caso o processo mundial fosse de padronização, as normas internacionais deveriam ser traduzidas e aplicadas sem qualquer ajuste. Harmonização: É amenizar as diferenças internacionais. Este é o processo que está sendo aplicado. Os pronunciamentos internacionais são traduzidos e adaptados às características de cada país, sem, entretanto, perder as características básicas de cada pronunciamento. Uniformidade: Com a harmonização mundial das normas contábeis as demonstrações contábeis de vários países serão comparáveis porque estarão uniformizadas de acordo com o padrão internacional, porém respeitando as características de cada país. Convergência: $O$ processo de implementação das normas internacionais em cada país.

Atualmente, o Brasil passou pelo processo de convergência das normas contábeis brasileiras aos padrões internacionais de Contabilidade, na tentativa de se atingir um nível de uniformidade entre as demonstrações contábeis brasileiras e as de outros países que aderirem a esse processo. De acordo com a Resolução CFC n $n^{\circ} 1.055 / 2005$, a crescente importância da internacionalização das normas contábeis vem levando inúmeros países a caminhar para um processo de convergência que apresente como conseqüência a redução de riscos nos investimentos internacionais, maior facilidade de comunicação internacional no mundo dos negócios com o uso de uma linguagem contábil, bem mais homogênea e capaz de reduzir o custo do capital existente nesse contexto.

O processo de convergência e harmonização das práticas contábeis já vem ocorrendo em vários países através da adoção de um conjunto de normas contábeis denominada International Financial Reporting Standards (IFRS), emitido pelo IASB. Conforme Padoveze, Benedicto e Leite (2011), esse processo de convergência tem ocorrido em três fases , $\mathbf{1}^{\mathrm{a}}$ fase: exigir das companhias de capital aberto o conjunto completo e mais complexo das normas contábeis internacionais; $\mathbf{2}^{\mathbf{a}}$ fase: exigir das companhias de capital fechado de grande porte o conjunto completo e mais complexo das normas contábeis internacionais; $\mathbf{3}^{\mathbf{a}}$ fase: 
exigir das pequenas e médias empresas um conjunto adaptado e menos complexo das normas contábeis internacionais.

No Brasil, esse processo de convergência foi iniciado pela CVM (Comissão de Valores Mobiliários), órgão regulador do mercado de capitais do país, o qual emitiu normas que aprovaram alguns pronunciamentos alinhados aos padrões internacionais. Não obstante as Leis $11.638 / 2007$ e 11.941/2009 alteraram, revogaram e introduziram novos dispositivos na Lei das Sociedades por Ações (Lei $\mathrm{n}^{\circ}$ 6.404, de 15 de dezembro de 1976), ocasionando mudanças importantes sobre as práticas contábeis brasileiras, visando à criação de condições necessárias para que o Brasil pudesse participar definitivamente do processo mundial de convergência das normas e práticas contábeis internacionais (International Accounting Standards - IAS e International Financial Reporting Standards - IFRS), emitidas pelo International Accounting Standards Board (IASB).

A Lei $n^{\circ} 11.638 / 2007$ teve origem no Projeto de Lei $n^{\circ} 3.741 / 2000$, de iniciativa da CVM junto ao Poder Executivo, cuja finalidade maior era possibilitar a eliminação de algumas barreiras regulatórias que impediam a inserção total das companhias abertas no processo de convergência contábil internacional, além de aumentar o grau de transparência das demonstrações financeiras em geral, inclusive em relação às chamadas sociedades de grande porte não constituídas sob a forma de sociedade por ações.

\subsection{Pronunciamento técnico - PME}

Em julho de 2009, o IASB emitiu o IFRS para pequenas e médias empresas (IFRS for SMEs - The International Financial Reporting Standards for Small and Medium Entities), que foi adaptado ao Brasil pelo CFC em 4 de dezembro de 2009 e incorporado às normas contábeis brasileiras por meio do Pronunciamento Técnico PME - Contabilidade para pequenas e médias empresas. Segundo a Resolução CFC nº 1.255/2009, que aprovou a Norma Brasileira de Contabilidade Técnica (NBC T) 19.41, a aplicação desse pronunciamento encontra-se em vigor desde $1^{\circ}$ de janeiro de 2010, destinado às pequenas e médias empresas para tratar da adoção de práticas contábeis em consonância com as normas internacionais emitidas pelo IASB (CFC, 2009). De acordo com o referido pronunciamento, são consideradas pequenas e médias empresas aquelas que apresentam as seguintes características: I - Não têm obrigação pública de prestação de contas; e II - Elaboram demonstrações contábeis para fins gerais (usuários externos). 
Assim as pessoas jurídicas abrangidas pelo Pronunciamento Técnico PME são as sociedades por ações de capital fechado (sem negociação de suas ações ou outros instrumentos patrimoniais ou de dívida no mercado), mesmo que obrigadas à publicação de suas demonstrações contábeis, desde que não enquadradas pela Lei no 11.638/2007 como sociedades de grande porte (empresas com ativo total superior a $\mathrm{R} \$ 240$ milhões no ano anterior ou receita bruta anual superior a $\mathrm{R} \$ 300$ milhões no ano anterior) e as sociedades limitadas e demais sociedades comerciais, desde que não enquadradas pela Lei $\mathrm{n}^{\circ}$ 11.638/2007 como sociedades de grande porte.

O Pronunciamento Técnico PME consiste numa versão simplificada do CPC completo, sendo um pronunciamento único e independente. Trata-se, portanto, de um texto menor em que foram eliminados princípios sobre operações complexas que raramente existiriam nas empresas de pequeno e médio porte, em que se verifica a opção pela simplificação dos reconhecimentos e mensurações, além da redução do volume e da complexidade das informações requeridas.

\subsection{Diferenças entre o pronunciamento técnico PME e o CPC completo}

O Pronunciamento Técnico PME consiste numa versão simplificada do CPC completo, sendo um pronunciamento único e independente. Trata-se, portanto, de um texto menor em que foram eliminados princípios sobre operações complexas que raramente existiriam nas empresas de pequeno e médio porte como, a não obrigação pública de prestação de conta e Elaboração das demonstrações contábeis para fins gerais para usuários externos, em que se verifica a opção pela simplificação dos reconhecimentos e mensurações, além da redução do volume e da complexidade das informações requeridas.

Como é possível observar, o objetivo das normas específicas para as pequenas e médias empresas consiste em adequar as práticas contábeis aos padrões internacionais, sem, contudo, ter todas as opções previstas no IFRS para as demais entidades, isso porque, se entende que houve uma preocupação em facilitar e reduzir os custos da implementação e manutenção das normas internacionais com relação aos benefícios que pudessem ser gerados nessas empresas.

Os estudiosos em IFRS comentam que o processo de adaptação do Brasil aos novos padrões internacionais das normas contábeis é de fundamental importância para a economia do país, alegam ainda que, o país encontrará vários obstáculos na inserção do processo de convergência contábil. A principal delas é a falta de profissionais capacitados em 
contabilidade internacional, dento e fora da área contábil. Para que ocorra a adaptação das empresas, faz-se necessário que seus profissionais adquiram os conhecimentos adequados para a adoção do padrão internacional (ESPERANTE, 2007).

Por meio da adoção das práticas contábeis em conformidade com o Pronunciamento Técnico PME, será possível às pequenas e médias empresas alcançarem uma linguagem contábil comum ou global que permitirá a eficiência na comunicação entre os usuários nacionais e estrangeiros, decorrente da comparabilidade, confiabilidade e da transparência das informações contábeis. Além da credibilidade perante os usuários externos, a implantação das novas práticas contábeis também pode impactar em melhorias na gestão dessas empresas. Nessa discussão, Bertão (2010) apresenta algumas opiniões de profissionais especialistas sobre os impactos da adoção do Pronunciamento Técnico PME no desenvolvimento das pequenas e médias empresas, conforme Quadro 1.

Quadro 1 - Impactos da adoção do Pronunciamento Técnico PME no desenvolvimento das PME's.

\begin{tabular}{|c|c|}
\hline $\begin{array}{l}\text { Ricardo Rodil } \\
\text { Conselheiro do } \\
\text { IBRACON }\end{array}$ & $\begin{array}{l}\text { A fase inicial de adequação das práticas contábeis em conformidade com o } \\
\text { CPC PME tem como principais desvantagens o custo de adaptação } \\
\text { (treinamentos, consultorias e contadores). }\end{array}$ \\
\hline $\begin{array}{l}\text { Antônio Castro } \\
\text { Presidente da } \\
\text { ABRASC Associação } \\
\text { Brasileira das } \\
\text { Abertas) }\end{array}$ & $\begin{array}{l}\text { É possível ver entre as empresas de grande porte que já adotaram o IFRS uma } \\
\text { tendência de queda dos spreads no ambiente de negócios. Isso acontece } \\
\text { porque a transparência e a acessibilidade ao balanço das companhias se } \\
\text { traduzem em redução de risco na visão de bancos e investidores. Todas as } \\
\text { partes interessadas naquele negócio têm o direito de saber se estão se } \\
\text { relacionando com uma empresa sustentável financeiramente, avaliar se é um } \\
\text { negócio saudável. Por isso, os bancos, por exemplo, começarão a solicitar } \\
\text { essas informações para emprestarem, assim como o sistema de crédito em } \\
\text { geral, destaca, ressaltando a importância do IFRS também para as pequenas e } \\
\text { médias empresas. }\end{array}$ \\
\hline $\begin{array}{l}\text { Ernesto Gelbcke } \\
\text { Sócio da Directa Auditores } \\
\text { e vice coordenador técnico } \\
\text { do CPC pela FIPECAFI }\end{array}$ & $\begin{array}{l}\text { Além da visibilidade, maior acesso ao crédito e custos reduzidos de } \\
\text { financiamento, a adoção de IFRS também é benéfica para a própria gestão da } \\
\text { empresa, pois a qualidade das informações atenderá tanto a terceiros, como a } \\
\text { gestão interna das organizações menores. Ele acredita que esse movimento } \\
\text { traz uma base única para a comparação das empresas de um mesmo setor, } \\
\text { com atividades parecidas, o que dá parâmetros de gestão. Adicionalmente as } \\
\text { empresas mais transparentes também levam vantagem quando buscam } \\
\text { parcerias ou até mesmo na comunicação com osstakeholderes, como } \\
\text { acionistas proprietários, investidores, empregados, clientes, fornecedores, } \\
\text { sindicatos, governos etc. }\end{array}$ \\
\hline Juarez Domingues & Com o Brasil no mesmo nível e qualidade contábil de outros países, o acesso \\
\hline
\end{tabular}




\begin{tabular}{|c|c|}
\hline $\begin{array}{l}\text { Carneiro } \\
\text { Presidente do CRC } \\
\text { (Conselho Federal de } \\
\text { Contabilidade) }\end{array}$ & $\begin{array}{l}\text { a investimentos, além da própria exposição de produtos e serviços no } \\
\text { mercado externo, também aumenta. Em sua visão, a sustentabilidade dos } \\
\text { negócios também implica na redução da mortalidade das empresas } \\
\text { brasileiras. }\end{array}$ \\
\hline $\begin{array}{l}\text { Reginaldo Alexandre } \\
\text { Presidente da } \\
\text { APIMEC-SP }\end{array}$ & $\begin{array}{l}\text { A obrigação das normas para pequenas e médias empresas não é uma } \\
\text { surpresa porque as autoridades brasileiras da área contábil já vinham } \\
\text { sinalizando, há algum tempo, a intenção de adotar o IFRS para todas as } \\
\text { companhias do país. }\end{array}$ \\
\hline
\end{tabular}

Fonte: Adaptado de Bertão (2010).

Como pode ser observado, se as pequenas e médias empresas adotarem o modelo IFRS, as mesmas estariam utilizando normas que podem favorecer a harmonização e, consequentemente, a comparabilidade, confiabilidade e transparência das informações contábeis entre empresas do mesmo porte e que atuam em segmento semelhante.

\section{METODOLOGIA}

Os procedimentos metodológicos adotados para o estudo estão classificados da seguinte forma: quanto à natureza (pesquisa exploratória), quanto aos objetivos (descritiva), quanto aos procedimentos (bibliográfica), quanto à abordagem do problema (qualitativa) (BEUREN, 2009).

Quanto ao universo e amostra, a população estudada é representada por profissionais da contabilidade de nível superior, técnico e acadêmico que atuam na região metropolitana do Recife-PE 2015.

A amostra utilizada nesta pesquisa foi do tipo não probabilística por acessibilidade ou conveniência. Na amostra por acessibilidade ou conveniência, segundo Gil (2002), o pesquisador apenas obtém os elementos a quem tem maior facilidade de acesso, admitindo que eles possam efetivamente representar de forma adequada à população. Assim, a amostra deste trabalho, foi constituída por 40 profissionais da contabilidade.

Quanto a coleta de dados o instrumento utilizado foi o questionário, que, de acordo com Beuren (2009), é constituído por uma série ordenada de perguntas que devem ser respondidas por escrito pelo informante. Serviram de base para a elaboração do questionário o Pronunciamento Técnico PME e o Manual da Contabilidade Societária: aplicável a todas as o sociedades de acordo com as normas internacionais e do CPC (IUDÍCIBUS et al., 2010). 
O questionário foi composto por 18 questões, com alternativas elaboradas de acordo com a literatura estudada, questões fechadas (em algumas alternativas foi sugerida a opção no corpo da questão de identificar mais de uma resposta), sendo dividido em quatro partes:

Parte 1 = caracterização do respondente (as 5 questões estão descritas no primeiro parágrafo da análise);

Parte 2 = Qualificação na busca do conhecimento sobre o processo de convergência contábil das pequenas e médias empresas aos padrões internacionais;

Parte 3 = Aplicação dos procedimentos contábeis em conformidade com o Pronunciamento Técnico PME;

Parte 4 = Principais contribuições obtidas através da adoção dos procedimentos contábeis em conformidade com o pronunciamento técnico PME.

Após a elaboração do questionário, foi realizado um pré-teste com três contadores (sendo professores de Contabilidade com titulação de mestre em Ciências Contábeis), no intuito de identificar possíveis vieses e interpretações ambíguas do instrumento. A aplicação do questionário foi realizada durante os meses de setembro a outubro de 2015. De um total de 40 questionários, 30 foram enviados por e-mail, obtendo-se as respostas de 26 contabilistas.

Quanto aos demais questionários, aplicados de forma direta junto com os contabilistas, onde foi possível obter o retorno de 14 opiniões, totalizando, assim, uma amostra de 40 questionários. A tabulação dos dados foi feita através do software Microsoft Office Excel 2007.

A limitação metodológica da pesquisa se refere ao uso da amostragem não probabilística por acessibilidade, que inviabiliza, em determinados casos como o do presente estudo, fazer inferências generalistas da população do estudo. A seguir estão expostos os resultados da pesquisa em torno da problemática abordada.

\section{ANÁLISE DOS RESULTADOS}

A Tabela 1 ilustra o perfil dos 40 respondentes da pesquisa. Percebe-se que a maioria é do sexo feminino (65\%) e está matriculada em um curso superior em contabilidade ou é bacharel em contabilidade (90\%). O setor de trabalho com maior representatividade é o setor contábil (50\%), sendo que a maioria dos respondentes não trabalha em escritório de contabilidade (60\%). O cargo de contador possui maior expressão na amostra (25\%) e a maior parte do tempo de atuação dos profissionais é de um a cinco anos. Nota-se que grande parte 
dos respondentes declarou não ter participado de treinamento sobre o CPC PME (97,5\%), assim como as empresas onde trabalham não o ofereceram (90\%).

Tabela 1 - Perfil dos respondentes

\begin{tabular}{|c|c|c|c|}
\hline Questões & Opções & $\begin{array}{l}\text { Quantidade dos } \\
\text { respondentes }\end{array}$ & $\%$ dos respondentes \\
\hline \multirow[t]{2}{*}{ Sexo } & Feminino & 26 & $65 \%$ \\
\hline & Masculino & 14 & $35 \%$ \\
\hline \multirow{5}{*}{ Formação } & Técnico & 3 & $8 \%$ \\
\hline & Graduando & 18 & $45 \%$ \\
\hline & Bacharel & 18 & $45 \%$ \\
\hline & Mestrado & 1 & $2 \%$ \\
\hline & Doutorado & 0 & $0 \%$ \\
\hline \multirow{2}{*}{$\begin{array}{c}\text { Trabalha em escritório } \\
\text { contábil }\end{array}$} & Sim & 16 & $40 \%$ \\
\hline & Não & 24 & $60 \%$ \\
\hline \multirow{6}{*}{ Cargo } & Contador & 10 & $25 \%$ \\
\hline & Assistente & 8 & $20 \%$ \\
\hline & Auxiliar & 8 & $20 \%$ \\
\hline & Trainee & 1 & $3 \%$ \\
\hline & Técnico & 4 & $10 \%$ \\
\hline & Analista & 9 & $22 \%$ \\
\hline \multirow{3}{*}{$\begin{array}{c}\text { Tempo de atuação na } \\
\text { área contábil }\end{array}$} & De 1 a 5 anos & 25 & $62 \%$ \\
\hline & De 5 a 10 anos & 11 & $28 \%$ \\
\hline & 10 anos ou mais & 4 & $10 \%$ \\
\hline \multirow{3}{*}{$\begin{array}{c}\text { Participou de } \\
\text { treinamento sobre CPC } \\
\text { PME }\end{array}$} & Sim & 1 & $2,5 \%$ \\
\hline & Não & 39 & $97,5 \%$ \\
\hline & & & \\
\hline \multirow{3}{*}{$\begin{array}{c}\text { O empregador já } \\
\text { ofereceu treinamento } \\
\text { sobre o CPC PME }\end{array}$} & Sim & 4 & $10 \%$ \\
\hline & Não & 36 & $90 \%$ \\
\hline & & & \\
\hline
\end{tabular}

Fonte: Dados da pesquisa.

A Tabela 2 apresenta o nível de conhecimento do profissional contábil sobre o CPC PME e o porte do benefício, adoção, obrigatoriedade, aplicação o os motivos que levara a esta aplicação segundo à ótica desses profissionais. A pesquisa revelou que a maior parte desses profissionais não leu o CPC PME (65\%) como também numa escala de 1 a 5 consideram o nível de conhecimento no menor nível (60\%). Acreditam que o benefício da adoção do CPC 
PME é pequeno (43\%), que ainda não é obrigatório (55\%), não é aplicável (73\%) e que o motivo da aplicação deve ser outros motivos (47\%).

Tabela 2 - Conhecimento, adoção, e aplicação do CPC PME

\begin{tabular}{|c|c|c|}
\hline Questões & Opções & $\begin{array}{c}\% \text { dos } \\
\text { respondentes }\end{array}$ \\
\hline \multirow[t]{3}{*}{ Você já leu o CPC PME? } & Sim & $35 \%$ \\
\hline & Não & $65 \%$ \\
\hline & 1 & $60 \%$ \\
\hline \multirow{4}{*}{$\begin{array}{c}\text { Em uma escala de } 1 \text { a 5, qual seu nível de } \\
\text { conhecimento adquirido referente ao CPC PME? }\end{array}$} & 2 & $20 \%$ \\
\hline & 3 & $20 \%$ \\
\hline & 4 & $0 \%$ \\
\hline & 5 & $0 \%$ \\
\hline \multirow{6}{*}{ Qual o porte do benefício da adoção? } & Pequeno & $43 \%$ \\
\hline & Médio & $25 \%$ \\
\hline & Grande & $8 \%$ \\
\hline & Nenhum & $12 \%$ \\
\hline & Não estou apto para & $12 \%$ \\
\hline & responder & \\
\hline \multirow{4}{*}{ À adoção do CPC PME é obrigatória? } & Sim & $38 \%$ \\
\hline & Não & $55 \%$ \\
\hline & Não estou apto para & \\
\hline & responder & $7 \%$ \\
\hline \multirow{5}{*}{$\begin{array}{l}\text { Em uma escala de } 1 \text { a 5, qual seu nível de aplicação } \\
\text { do CPC PME? }\end{array}$} & 1 & $73 \%$ \\
\hline & 2 & $15 \%$ \\
\hline & 3 & $7 \%$ \\
\hline & 4 & $5 \%$ \\
\hline & 5 & $0 \%$ \\
\hline \multirow{6}{*}{ Quais os motivos da aplicação do CPC PME? } & Iniciativa do contador & $18 \%$ \\
\hline & Iniciativa do gestor & $13 \%$ \\
\hline & Obter financiamento & $2 \%$ \\
\hline & Outras & $47 \%$ \\
\hline & Não estou apto para & \\
\hline & responder & $20 \%$ \\
\hline
\end{tabular}

Fonte: Dados da pesquisa

A Tabela 2 evidencia a falta de conhecimento e aplicação do CPC PME por grande parte dos profissionais contábeis e a falta de aptidão para responder questões que tratam do CPC PME. Também desconhecem sua obrigatoriedade de acordo com a Resolução CFC 1.255/2009, aprovou a NBC T 19.41 que trata especificamente sobre às regras aplicáveis na 
Contabilidade de pequenas e médias empresas que adequa as empresas à convergência contábil.

A Tabela 3 evidencia o meio que o profissional contábil vem buscando para se qualificar e entender o CPC PME, sendo através de vário meios com exemplo da internet (blogs, artigos, revistas eletrônicas), livros, revistas e o próprio CPC PME além de palestras e seminários. Nestas perguntas os profissionais contábeis podem marcar mais de uma opção.

Tabela 3 - Meios utilizados para capacitação sobre o pronunciamento CPC PME

\begin{tabular}{cc}
\hline Opções & \% dos respondentes \\
\hline Palestras e seminários & $21 \%$ \\
Livros, revistas e Pronunciamento \\
Técnico PME & $8 \%$ \\
Internet (artigos, blogs e revistas eletrônicas) & $27 \%$ \\
Nenhum meio de capacitação sobre o Pronunciamento & $27 \%$ \\
Técnico PME & $17 \%$ \\
\hline Não estou apto para responder & \\
\hline
\end{tabular}

Fonte: Dados da pesquisa

Vale comentar sobre a importância de haver um esforço do profissional contábil no que se refere à busca pela capacitação continuada, para que se possam adotar as práticas contábeis em consonância com os padrões internacionais também nas pequenas e médias empresas.

A Tabela 4 apresenta que $40 \%$ dos respondentes não se sentem aptos a responder sobre a sequência das fases referentes ao processo de adoção das normas contábeis internacionais. Esse resultado pode ser decorrente da falta de clareza ou até mesmo da utilização desses termos como sinônimos por muitos autores. Conforme apresentado na revisão da literatura, Perez Junior (2009) afirma que a sequência correta é inicialmente o processo de convergência das normas contábeis aos padrões internacionais, ao término desse processo se dá a harmonização, havendo, consequentemente, a uniformidade das demonstrações contábeis de todos os países que aderirem às normas internacionais.

Tabela 4 - Sequência de fases correta com relação ao processo de adoção das normas internacionais emitidas pelo IASB 


\begin{tabular}{cc}
\hline Convergência - padronização - uniformização & $14 \%$ \\
\hline Convergência - harmonização - uniformização & $20 \%$ \\
Convergência - uniformização - harmonização & $13 \%$ \\
Convergência - uniformização - padronização & $13 \%$ \\
Não estou apto para responder & $40 \%$ \\
\hline
\end{tabular}

Fonte: Dados da pesquisa

A Tabela 5 evidencia quais demonstrações contábeis são obrigatórias da acordo com o CPC PME. Além do BP, da DRE e do Fluxo de Caixa, a elaboração da Demonstração do Resultado Abrangente, bem como da Demonstração das Mutações do Patrimônio Líquido e elaboração das Notas Explicativas são determinadas como obrigatórias pelo Pronunciamento Técnico PME. Apesar dos demonstrativos serem apresentados de forma mais simplificada nas pequenas e médias empresas, a elaboração da DRA, da DMPL e das Notas Explicativas podem complementar as informações que normalmente são disponibilizadas aos usuários no processo de tomada de decisões. Nestas perguntas os profissionais contábeis podem marcar mais de uma opção.

Tabela 5 - Demonstrações contábeis obrigatórias para as pequenas e médias empresas de acordo com CPC PME

\begin{tabular}{cc}
\hline Questões & \% dos respondentes \\
\hline Balanço patrimonial (PB) & $21 \%$ \\
\hline Demonstração do resultado do exercício (DRE) & $18 \%$ \\
Demonstração do resultado do abrangente (DRA) & $11 \%$ \\
Demonstração das mutações do patrimônio líquido (DMPL) & $10 \%$ \\
Demonstração do fluxo de caixa (DFC) & $13 \%$ \\
Notas explicativas & $8 \%$ \\
Demonstração do valor adicionado (DVA) & $2 \%$ \\
Não estou apto para responder & $17 \%$ \\
\hline
\end{tabular}

Fonte: Dados da pesquisa

A Tabela 5 demonstra que os profissionais contábeis enfatizaram a obrigatoriedade da elaboração do Balanço Patrimonial, seguido da Demonstração do Resultado do Exercício, como também da Demonstração do Fluxo de Caixa. Entende-se que esse resultado se 
apresenta desta forma devido ao fato de os contabilistas da amostra do estudo já elaboravam esses demonstrativos antes mesmo do Pronunciamento Técnico PME.

No que se refere à Tabela 6 trata da ótica do profissional contábil nos objetivos das demonstrações contábeis elaborada de acordo com o CPC PME.

Tabela 6 - Objetivo das demonstrações contábeis preparadas de acordo com o PCP PME

\begin{tabular}{cc}
\hline Opções & \% dos respondentes \\
\hline Atender às exigências do Fisco & $17 \%$ \\
Fornecer informações úteis a uma gama de usuários que não estão em \\
uma posição de solicitar relatórios adaptados para atender suas \\
necessidades. & $33 \%$ \\
Particulares de informação & $5 \%$ \\
Não estou apto para responder & $55 \%$ \\
\hline
\end{tabular}

Fonte: Dados da pesquisa

Podemos perceber um percentual significativo dos respondentes acerca do correto entendimento sobre o objetivo das demonstrações contábeis preparadas de acordo com o CPC PME, ou seja, fornecer informações úteis aos vários tipos de usuários, entretanto, a maior parte dos respondentes não se sente apto apara responder por ainda desconhecerem qual o objetivo das demonstrações contábeis elaboradas de acordo com o pronunciamento.

A Tabela 7 representa o conhecimento dos profissionais contábeis na mensuração dos estoques de acordo com o CPC PME.

Tabela 7 - Como deve ser feita a mensuração dos estoques

\begin{tabular}{cc}
\hline Opções & \% dos respondentes \\
\hline Admite-se o preço de compra mais recente. Este é aquele que se & \\
aproxima do "inventário periódico" praticado por muitas empresas. & $25 \%$ \\
Pelo menor valor entre o custo e o valor realizável líquido & $17 \%$ \\
Não estou apto para responder & $58 \%$ \\
\hline
\end{tabular}

Fonte: Dados da pesquisa

Infere-se que o estoque é um item do ativo relevante, que merece atenção quanto ao seu reconhecimento, mensuração e evidenciação. Conforme determina o Pronunciamento Técnico CPC 16, a regra para fins de mensuração dos estoque é: "valor de custo ou realizável líquido, 
dos dois o menor" (IUDÍCIBUS et al.2013). Na tabela 7, apenas (17\%) dos respondentes responderam a opção correta e (58\%) dos respondentes não sentem-se aptos a responder desconhecendo como deve ser feita a mensuração dos estoques.

A Tabela 8 enfatiza o tratamento contábil que deve ser dado à mensuração de propriedade para investimento em pequenas e médias empresas de acordo com o pronunciamento técnico PME.

Tabela 8 -Propriedade para investimento (terras ou edificações com a intenção de receber aluguel, para valorização do capital ou ambos)

\begin{tabular}{lc}
\hline \multicolumn{1}{c}{ Opções } & \% dos respondentes \\
\hline Pode ser avaliado pelo "valor justo", quando este puder ser mensurado de & \\
forma confiável, sem custos ou esforços indevidos e de forma contínua. & $30 \%$ \\
Entende-se por valor justo o montante pelo qual um ativo poderia ser & \\
trocado, ou um passivo liquidado entre partes independentes, com & \\
conhecimento do negócio e interesse em realizá-lo, em uma transação em & $3 \%$ \\
que não há favorecidos. & $67 \%$ \\
Somente deve ser contabilizado como ativo imobilizado usando o método de & \\
custo menos depreciação, menos redução ao valor recuperável. & \\
\hline
\end{tabular}

Fonte: Dados da pesquisa

Importante destacar, no que se refere à mensuração da propriedade para investimento, que menos da metade dos respondentes já tem o entendimento do conceito de valor justo, respondendo que a mensuração das terras ou edificações com intenção de receber aluguel para valorização do capital deve ser feita considerando o valor do ativo em uma transação sem favorecimentos alinhados ao que determina o Pronunciamento Técnico PME, quando este puder ser avaliado de forma confiável, sem custos ou esforços indevidos.

As Tabelas 9 e 10 demonstram como o profissional contábil mensura e amortiza o ágio por expectativa de rentabilidade futura ou goodwill em pequenas e médias empresas de acordo com o processo de convergência.

Tabela 9 - Mensuração do ágio por expectativa de rentabilidade futura ou goodwil 


\begin{tabular}{cc}
\hline É definido como ativo intangível com vida útil indefinida, não podendo & \\
ser amortizado. & $7 \%$ \\
\hline Deve ser considerado um ativo intangível com vida útil finita. Caso & \\
seja impossível fazer uma estimativa confiável da vida útil presume-se & $23 \%$ \\
o período de $\mathbf{1 0}(\mathbf{d e z})$ anos & $70 \%$ \\
Não estou apto para responder & \\
\hline
\end{tabular}

Fonte: Dados da pesquisa

Relevante destacar que o ágio gerado por expectativa de rentabilidade futura só deve ser contabilizado no processo de combinação de negócios (CPC 15) e que de acordo com este pronunciamento a vida útil deste ativo intangível é indefinida para as empresas de grande porte. No entanto para as PME todo o ágio por expectativa de rentabilidade futura (goodwill) é amortizado, isto é, considera-se que se possui vida útil limitada. Caso não seja possível estimar a vida útil de maneira confiável, deve-se considerá-la como sendo de 10 anos. Relevante destacar também que a maioria dos respondentes $(70 \%)$ não se sentiu aptos para responder.

Tabela 10 - Amortização do ágio por expectativa de rentabilidade futura ou goodwil

\begin{tabular}{cc}
\hline Opções & \% dos respondentes \\
\hline O método de amortização deve ser revisto pelo menos a cada exercício. & $7 \%$ \\
O método de amortização é revisto somente se houver uma indicação & $18 \%$ \\
de alteração significativa no uso do ativo desde o último encerramento & $75 \%$ \\
\hline
\end{tabular}

Fonte: Dados da pesquisa

O quesito da Tabela 10 merece atenção, uma vez que $75 \%$ dos respondentes não se sentiram aptos a responder e $7 \%$ se equivocaram quanto ao método de amortização adotado para as pequenas e médias empresas no que diz respeito ao ágio gerado por expectativa de rentabilidade futura ou goodwill. De acordo com o Pronunciamento Técnico PME, o valor residual, a vida útil e o método de amortização necessitam ser revistos apenas quando existir uma indicação relevante de alteração, isto é, não necessitam ser revistos anualmente como preconizado no IFRS completo. 
Quanto à mensuração dos gastos com pesquisa e desenvolvimento nas pequenas e médias empresas, em nenhum caso podem ser ativados, verificando-se na Tabela 11.

Tabela 11 - Gastos com pesquisa e desenvolvimento

\begin{tabular}{cc}
\hline Opções & \% dos respondentes \\
\hline Todos os custos de pesquisa e desenvolvimento são reconhecidos como & $7 \%$ \\
despesa. & $35 \%$ \\
Os gastos com pesquisa devem ser reconhecidos como despesa, \\
enquanto que os gastos com desenvolvimento podem ser \\
$\begin{array}{c}\text { classificados como ativo intangível quando atendidos critérios } \\
\text { Não estou apto para responder }\end{array}$ \\
\hline
\end{tabular}

Fonte: Dados da pesquisa

Observa-se que apenas $35 \%$ dos respondentes tem o correto conhecimento sobre a temática, enquanto os demais ou responderam errado ou afirmaram não estarem aptos a responder a questão.

A Tabela 12 trata sobre a reavaliação de ativos e o tratamento que o deve ser dado de acordo com o CPC PME.

Tabela 12 - Reavaliação de ativos

\begin{tabular}{cc}
\hline Opções & \% dos respondentes \\
\hline Pode ser aceita se a lei permitir & $40 \%$ \\
É vedada. & $10 \%$ \\
Não estou apto para responder & $50 \%$ \\
\hline
\end{tabular}

Fonte: Dados da pesquisa

No que ser refere ao procedimento da reavaliação dos ativos, que consiste na adoção do valor de mercado para os bens reavaliados, em substituição ao princípio do registro pelo valor original, observa-se que apenas (10\%) afirmam que a reavaliação é vedada (sendo a opção correta). No entanto esse procedimento é vedado para as pequenas e médias empresas, conforme o Pronunciamento Técnico PME. Percebe-se que a maioria dos respondentes desconhece a nova normatização que trata de reavaliação de ativo.

A Tabela 13 demonstra a ótica do profissional contábil no tratamento dado ao ajuste do valor presente de acordo com os conhecimentos técnicos dos mesmos e usados usualmente no dia-a-dia. 
Tabela 13 - Ajuste ao valor presente

\begin{tabular}{cc}
\hline Opções & \% dos respondentes \\
\hline Significa que os efeitos financeiros devem ser considerados nas receitas e & $23 \%$ \\
compras & $15 \%$ \\
Significa que os efeitos financeiros não devem ser incluídos no valor das \\
receitas e compras \\
Não estou apto para responder & $62 \%$ \\
\hline
\end{tabular}

Fonte: Dados da pesquisa

Verifica-se na Tabela 13, que mais de $23 \%$ informaram que o ajuste ao valor presente significa que os efeitos financeiros devem ser considerados nas receitas e despesas. Dessa forma, ativos e passivos monetários com juros implícitos ou explícitos embutidos devem ser mensurados pelo seu valor presente quando do seu reconhecimento inicial.

A Tabelas 14 e 15 apresentam os resultados sobre a opinião dos respondentes acerca dos benefícios e impactos da CPC PME.

Tabela 14 - Benefícios que podem ser gerados às empresas de pequeno e médio porte com a adoção de práticas contábeis em conformidade com o Pronunciamento Técnico PME (possibilidade de marcar mais de uma opção)

\begin{tabular}{cc} 
Questões & \% dos respondentes \\
\hline $\begin{array}{c}\text { Maior facilidade na obtenção de recursos por meio de financiamentos } \\
\text { e/ou abertura de capital }\end{array}$ & $11 \%$ \\
Maior comparabilidade do desempenho entre as empresas que atuam & $17 \%$ \\
no mesmo segmento de negócio independente da localização & $15 \%$ \\
Maior conhecimento do negócio pelos gestores das entidades & $5 \%$ \\
Não identifico, pois entendo que a adoção das práticas contábeis em \\
consonância com as normas internacionais só beneficiarão as \\
empresas de grande porte enquadradas pela Lei no $11.638 / 2007$ \\
Não estou apto para responder & $52 \%$ \\
\hline
\end{tabular}

Fonte: Dados da pesquisa 
A Tabela 14 revela que (5\%) dos respondentes não identificam possíveis benefícios que podem ser gerados às empresas de pequeno e médio porte com a adoção de práticas contábeis em conformidade com o Pronunciamento Técnico PME. Para estes contabilistas, a adoção das práticas contábeis em consonância com as normas internacionais só beneficiará as empresas de grande porte enquadradas pela Lei ${ }^{\circ} 11.638 / 2007$.

Tabela 15 - De que forma a exigência da adoção de práticas contábeis em conformidade com o Pronunciamento Técnico PME vai implicar na atividade do profissional contabilista (possibilidade de marcar mais de uma opção)

\begin{tabular}{cc}
\hline Questões & \% dos respondentes \\
\hline trabalho & $25 \%$ \\
Haverá uma maior valorização deste profissional no mercado de & $15 \%$ \\
Possibilidade de atender a real finalidade da contabilidade & $8 \%$ \\
Aumento de custos com adaptação de plano de contas, sistemas, & \\
treinamento, será necessário mais tempo para fazer a contabilidade de & \\
cada cliente & $4 \%$ \\
Representa maiores responsabilidades por parte do contabilista, não & $48 \%$ \\
evidenciando nenhum benefício para a profissão & \\
Não estou apto para responder &
\end{tabular}

Fonte: Dados da pesquisa

Através dos dados da Tabela 15, observa-se que há um entendimento por parte dos respondentes $(25 \%)$ de que a adoção das práticas contábeis em conformidade com o Pronunciamento Técnico PME resultará numa maior valorização do profissional contábil. É relevante destacar que, na percepção dos investigados, as novas mudanças na prática contábil possibilitarão o atendimento da real finalidade da contabilidade, que é de gerar o máximo de informações que possam subsidiar seus usuários no processo de tomada de decisão.

\section{CONCLUSÃO}

O presente estudo procurou identificar a percepção do profissional contábil no processo de convergência nas pequenas e medias empresas na região metropolitana do Recife, PE.

Percebe-se neste estudo que a maioria dos respondentes é do sexo feminino e que grande parte declarou não ter participado de treinamento por conta própria sobre o CPC PME, assim como as empresas onde trabalham não o ofereceram. Entretanto, os respondentes 
afirmam, em sua maioria, que vem buscando se qualificar e entender o CPC PME (sobre a convergência da contabilidade das pequenas e médias empresas aos padrões internacionais) por meio de informações sobre o assunto através da internet (artigos, blogs e revistas eletrônicas); leitura de livros, revistas e do próprio CPC PME; além de palestras e seminários.

Com relação às fases do processo de adoção das normas contábeis internacionais, apesar de um percentual significativo dos respondentes afirmarem que têm buscado informações sobre o tema, muitos não souberam identificar que esse processo se inicia com a convergência, ao término desse processo se dá a harmonização, havendo, consequentemente, a uniformidade das demonstrações contábeis de todos os países que aderirem às normas internacionais. No que se refere à identificação das principais práticas contábeis adotas por esses profissionais da contabilidade de acordo com o Pronunciamento Técnico PME, verificou-se que os respondentes enfatizaram a obrigatoriedade da elaboração do Balanço Patrimonial, da Demonstração do Resultado do Exercício, como também da Demonstração do Fluxo de Caixa, sem incluir também a elaboração da Demonstração do Resultado Abrangente, bem como da Demonstração das Mutações do Patrimônio Líquido e elaboração das Notas Explicativas.

Nesse contexto, a pesquisa ainda revelou que um percentual significativo dos respondentes entende que o objetivo das demonstrações contábeis preparadas de acordo com o Pronunciamento Técnico PME é de fornecer informações úteis a uma gama de usuários (por exemplo: investidores e credores) que não estão em uma posição para solicitar relatórios adaptados para atender às suas necessidades particulares de informação. Quando estes profissionais contábeis foram questionados sobre a mensuração dos estoques de acordo com o Pronunciamento Técnico PME, mais da metade responderam alinhados com a prática usual que se admite o preço de venda mais recente. No que se refere à mensuração da propriedade para investimento, admite-se que pelo menos a metade dos respondentes já tem o entendimento do conceito de valor justo, respondendo que a mensuração das terras ou edificações com intenção de receber aluguel para valorização do capital deve ser feita considerando o valor do ativo em uma transação sem favorecimentos. Sobre a mensuração do ágio por expectativa de rentabilidade futura ou goodwill, observa-se que a maioria não se sentiu apta a responder. Quanto às respostas em relação à amortização dos bens intangíveis, dos gastos com pesquisa e desenvolvimento, bem como sobre a reavaliação dos ativos também não estavam em conformidade com o Pronunciamento Técnico PME. Sobre o ajuste 
ao valor presente, uma boa parte dos respondentes identificou que os juros devem ser segregados das receitas e compras, o que gera um questionamento se realmente tem se aplicado na prática esse conceito.

Diante dos resultados obtidos, é possível concluir que os profissionais contábeis que atuam na Região Metropolitana do Recife - PE não desconhecem totalmente o atual processo de convergência da contabilidade brasileira aos padrões internacionais, no entanto, a ótica dos investigados quanto aos procedimentos contábeis em conformidade com o Pronunciamento Técnico destinado às pequenas e médias empresas tem ocorrido quando as práticas coincidem com aquelas que usualmente já estavam sendo executadas de uma forma pragmática, como pode ser observado na mensuração dos estoques, na elaboração do Balanço Patrimonial, da Demonstração do Resultado do Exercício e Demonstração do Fluxo de Caixa. Identificou-se, também, em nossa pesquisa que esses profissionais têm consciência da necessidade da qualificação continuada e dos benefícios que podem resultar às empresas e ao próprio profissional contábil, em virtude da adoção de práticas contábeis em conformidade com os padrões internacionais nas pequenas e médias empresas.

A limitação deste estudo encontra-se no tamanho da amostra, tendo em vista que foram aplicados apenas 40 questionários e somente aos profissionais contábeis que atuam na Região Metropolitana do Recife - PE. Recomenda-se ampliar a amostra incluindo profissionais contábeis de outras regiões, uma vez que o processo de convergência da contabilidade aos padrões internacionais abrange esses profissionais em todo o país. Para as novas pesquisas sugere-se: explorar o tema de forma mais específica, abordando a aplicabilidade dos principais procedimentos apresentados pelo Pronunciamento Técnico PME, identificar os reais impactos em uma empresa de pequeno ou médio porte que tenha a sua contabilidade adequada ao Pronunciamento Técnico PME e/ou verificar se já existem contabilistas adotando em sua plenitude o Pronunciamento Técnico PME.

\section{REFERÊNCIAS}

AMENÁBAR, Ana M. H. Harmonização contábil em cinco países da América do Sul. 2001. Dissertação (Mestrado em Contabilidade) - Universidade de São Paulo. São Paulo: USP,2001. Disponível em: <http://www.teses.usp.br/teses/disponiveis/12/12136/tde06062002-112701/pt-br.php>. Acesso: 24 ago. 2015. 
BERTÃO, Naiara. IFRS bate à porta das pequenas e médias empresas. Ibef News, Porto Alegre, v. 144, p. 34-42, jun. 2010. Disponível em: <http://www.ibef.com.br/ibefnews/pdfs/144/materiadecapa.pdf>. Acesso em: 20 ago. 2015.

BEUREN, Ilse Maria. Como elaborar trabalhos monográficos em contabilidade: teoria e prática. 3.ed. São Paulo: Atlas 2009.

BRASIL. Lei $\mathrm{n}^{\circ} 11.638$, de 28 de dezembro de 2007. Altera e revoga dispositivos da Lei $\mathrm{n}^{\circ}$ 6.404, de 15 de dezembro de 1976, e da Lei $\mathrm{n}^{\circ}$ 6.385, de 7 de dezembro de 1976, e estende às sociedades de grande porte disposições relativas à elaboração e divulgação de 19 demonstrações financeiras. Diário Oficial [da] República Federativa do Brasil. Brasília, 28 dez.2007. Disponível em: <http://www.planalto.gov.br/ccivil_03/_Ato2007-2010/2007/Lei/

L11638.htm>. Acesso em: 9 set. 2015.

. Lei no 11.941, de 27 de maio de 2009. Diário Oficial da República Federativa do Brasil. $\quad$ Brasília, 28 mai.2009. Disponível em:<http://www.planalto.gov.br/ccivil_03/_Ato2007-

2010/2009/Lei/L11941.htm. Acesso em: 9 dez. 2011. CFC. Conselho Federal de Contabilidade. Resolução CFC $\mathrm{n}^{\circ} 1.055$, de 7 de outubro de 2005. Cria o Comitê de Pronunciamentos Contábeis (CPC), e dá outras providências. Diário Oficial da União, Brasília, 24 out. 2005.2 Disponível <http://crcsp.org.br/portal_novo/legislacao_contabil/resolucoes/Res1055.htm>. Acesso em: 7 set. 2015 .

Resolução CFC nº 1.255, de 10 de dezembro de 2009. Aprova a NBC TG 1000 -

Contabilidade para Pequenas e Médias Empresas. Diário Oficial da União, Brasília, 17 dez. 2009. Disponível em: <http://crcsp.org.br/portal_novo/legislacao_contabil/resolucoes/ Res1095.htm>. Acesso em: 7 agos. 2015.

CPC. Comitê de Pronunciamentos Contábeis. Pronunciamento Técnico PME: contabilidade para pequenas e médias empresas. Brasília: CPC, 2009. Disponível em:

<http://www.cpc.org.br/pdf/CPC_PMEeGlossario_R1.pdf>. Acesso em: 3 jul. 2015.

GIL, Antônio Carlos. Como elaborar projetos de pesquisa. 4. ed. São Paulo: Atlas, 2002

GIROTTO, Maristela. Brasil começa a adotar o IFRS na contabilidade de PMEs. Revista Brasileira de Contabilidade, Brasília, v. 186, p. 7-23, nov./dez. 2010. Disponível em: 
<http://www.fucape.br/downloads/reportagem_rbc_186.pdf>. Acesso em: 4 set. 2015.

IFRS EXPRESS. Locais da adoção na IFRS ao redor do mundo. São Paulo, 23 set. 2008. Disponível em: <http://ifrsexpress.blogspot.com/2008/09/locais-da-adoo-na-ifrs-ao-redordo.html>.Acesso em: out. 2015.

IUDÍCIBUS, Sérgio; MARTINS, Eliseu; GELBCKE, Ernesto Rubens; SANTOS, Ariovaldo dos. Manual de contabilidade societária: aplicável a todas as sociedades de acordo com as normas internacionais e do CPC - Fipecafi. São Paulo: Atlas, 2010.

Manual de contabilidade societária: aplicável a todas as sociedades de acordo com as normas internacionais e do CPC - Fipecafi. 2. ed. São Paulo: Atlas, 2013.

SANTOS, Ariovaldo dos. Alguns pontos da Lei 11.638 e a internacionalização da Contabilidade brasileira. Ibef News. Porto Alegre, v. 115, p. 28-30, mar. 2008. Disponível em:<http://www.ibef.com.br/ibefnews/pdfs/115/artigo.pdf>. Acesso: 9 out. 2015.

PADOVEZE, Clóvis Luís; BENEDICTO, Gideon Carvalho de; LEITE, Joubert da Silva Jerônimo. Manual de contabilidade internacional: IFRS - US Gaap - BR Gaap: teoria e prática.São Paulo: Cengage Learnig, 2011.

PEREZ JUNIOR, José Hernandez. Conversão das demonstrações contábeis. 7. ed. São Paulo:Atlas, 2009.

SEBRAE. Sobrevivência e mortalidade das empresas paulistas de 1 a 5 anos. Marco Aurélio Bedê (Coordenador). São Paulo: SEBRAE, 2004 Disponível em: <http://www.biblioteca.sebrae.com.br/bds/bds.nsf/DED986F2676BD261832572BC0063F7A A/\$File/NT00035176.pdf>. Acesso em: 12 jul. 2015. 